\title{
Tradicija i uvjeti uzgoja vinove loze u vinogorju Baranja
}

\section{Sažetak}

Osnovni čimbenik koji određuje uzgoj vinove loze jest klima. Ta tvrdnja se može prikazati pomoću broja sunčanih sati i sume efektivnih temperatura. Republika Hrvatska svojim geografskim položajem pronalazi svoje mjesto na vinogradarskoj karti svijeta. Vinova loza se stoljećima uzgaja na području današnje vinogradarske podregije Podunavlje, koja obuhvaća vinogorja Srijem, Erdut i Baranju. Podaci korišteni u ovom radu, vezani su uz 2013. godinu za vinogorje Baranja.

Ključne riječi: klima, Podunavlje, vinogorje Baranja

\section{Uvod}

Zahvaljujući raznolikosti reljefa, klime i tla, te niza drugih čimbenika, u Republici Hrvatskoj (RH) postoji velika mogućnost proizvodnje kvalitetnih i vrhunskih vina. U svijetu se govori o pet vinogradarskih zona koje se kategoriziraju prema sumi efektivnih temperatura koje predstavljaju (Winkler, 1974; Fazinić i Fazinić, 1997). Prema toj klasifikaciji, RH ima četiri zone (Maletić i sur., 2008), a Hrvatsko Podunavlje, koje je zajedno sa Slavonijom prema Zakonu o vinu (NN, $32 / 19$ ) jedna od četiri nove vinogradarske regije, nalazi se u uvjetima vinogradarske proizvodne zone C1 sa sumom efektivnih temperatura $1450-1650{ }^{\circ} \mathrm{C}$. Jedan od najvažnijih čimbenika koji diktiraju uzgoj vinove loze je klima (van Leeuwen i sur., 2004; Jackson, 2008). Stoga, uzgoj grožđa odvija se uglavnom između $30^{\circ}$ i $50^{\circ}$ sjeverne, te $30^{\circ}$ i $40^{\circ}$ južne geografske širine (Jackson, 2001). Hrvatska se cijelim svojim ozemljem nalazi unutar umjerenog klimatskog pojasa, između $42^{\circ} 25^{\prime}$ i $46^{\circ} 30^{\prime}$ sjeverne geografske širine, koji joj pruža vrlo povoljne klimatske uvjete za uzgoj vinove loze u gotovo svim dijelovima, osim u Lici i Gorskom kotaru (Gašparec-Skočić i Bolić, 2006). Vinogradi u kontinentalnim područjima (Međimurje, Zagorje, Prigorje, Pokuplje, Moslavina, dijelovi Slavonije, Podunavlje) položeni su na sunčanim stranama brežuljaka, na visini između 110 i 350 m (Maletić i sur., 2015). Vinova loza je vrlo prilagodljiva i otporna na različite klimatske i reljefne uvjete. Izvjesnu prednost pred ostalim kulturama postiže jer uspijeva tamo gdje druge kulture gotovo da ne mogu ni opstati, kao što su oskudna kamenita i pjeskovita tla primorske Hrvatske, te strmi tereni kontinentalne Hrvatske (Fazinić i Milat, 1994).

\section{Podregija Podunavlje}

Podunavlje je najistočnija hrvatska vinogradarska podregija. Hrvatsko Podunavlje je tipično panonsko područje koje karakterizira izrazito ravničarski reljef. Na tim ravnicama uglavnom su smješteni i najveći vinogradarski proizvodni kompleksi. Na području Baranje i Srijema nalaze se neka od najplodnijih tala u $\mathrm{RH}$, prema sistematizaciji to su černozem, eutrično smeđe tlo $\mathrm{i}$ rigolano tlo na lesu (P1 kategorija tala) (Mirošević i sur., 2009). Tradicija uzgoja vinove loze u području ove podregije seže u 3. stoljeće, kada su je sadili Rimljani na obroncima Fruške gore, a zatim se širila po cijeloj regiji. Čuvena antička tradicija uspješno je nastavljena i njegovana tijekom srednjeg vijeka, s duljom stankom za vrijeme opsade Turaka. Nakon njihovog odla- 
ska, novi gospodari, kasnosrednjovjekovne plemićke loze Odeschalchi, Eltz, Chech, te Savojski vojvode, vratili su stare običaje uzgoja vinove loze koji se na istim položajima njeguju i danas (HGK, 2011). Od tada pa do danas postoje brojni zapisi koji svjedoče o kvaliteti vina i značaju ove proizvodnje za gospodarstvo - vinova loza je postala jedna od najznačajnijih poljoprivrednih kultura u Slavoniji i Hrvatskom Podunavlju. U geografskom smislu, rasprostire se od Virovitice i Daruvara na zapadu do Dunava na istoku (Slika 1), obuhvaćajući najljepše i vrlo raznolike položaje gdje se vinova loza tradicionalno uzgaja. Glavnina vinograda je smještena na pitomim i prostranim obroncima planina Dilja, Psunja, Požeške gore, Papuka, Krndije i Fruške gore (Vina Croatia). Vinogradi se nalaze na nadmorskim visinama od $100 \mathrm{~m}$ (okolica Vukovara) do $240 \mathrm{~m}$ (obronci Fruške gore, Baranjskog brda, Erdutskog i Banskog brda) (Maletić i sur., 2015). Oštre zime, prohladna proljeća, vrela ljeta i umjereno tople jeseni, glavne su klimatske karakteristike koje ovu ljupku podregiju čine idealnom za uzgoj mnogih sorti vinove loze. Iznimno je važno da se sade na spomenutim obroncima, jer su ravničarske depresije kojima ovaj kraj obiluje podložne jesenskom truljenju zbog slabog strujanja zraka te zimskom smrzavanju, a ono, kada se dogodi, zahtijeva vađenje kompletnih vinograda (HGK, 2011).

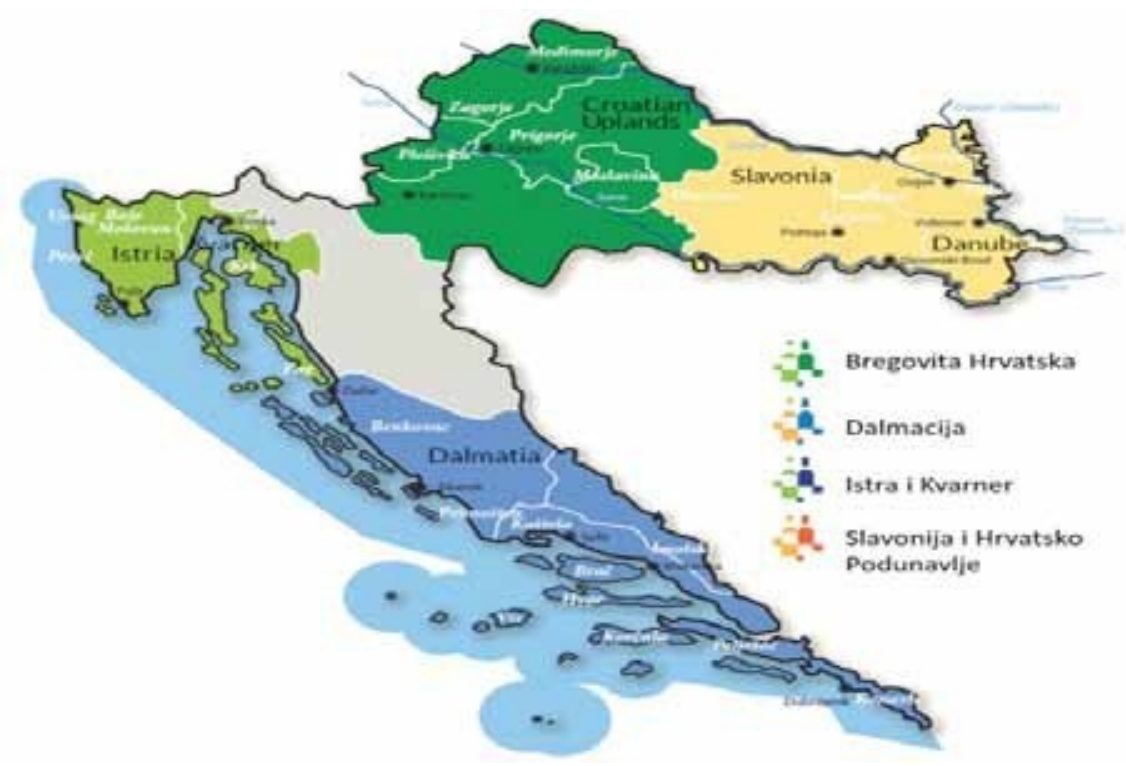

Slika 1. Prikaz vinogradarskih regija Hrvatske

Figure 1. Overview of viticultural regions of the Republic of Croatia

Izvor/Source: Vina Croatia

Najzastupljenija podloga u ovoj podregiji je Kober 5BB, podloga nastala križanjem američkih vrsti roda Vitis, i to Vitis berlandieri $x$ Vitis riparia. Podloga ima relativno kratak vegetacijski ciklus, dobro podnosi sve vrste tala, kao i vrlo dobar afinitet sa svim kultivarima Vitis vinifere i vrlo visok postotak ukorjenjivanja. Dobro utječe na visinu i kakvoću prinosa. Otporna je na filokseru, kriptogamne bolesti, te na niske zimske temperature (Mirošević i Karoglan Kontić, 2008). S obzirom na obradiva tla na kojima su podignuti vinogradi, moguća je primjena najsuvremenije mehanizacije što je jedan od uvjeta visoke produktivnosti. Stoga, posljednjih godina, posebice s podunavskih položaja proizvode se crna vina sa zaštićenom oznakom izvornosti ili zaštićenom oznakom zemljopisnog podrijetla. Na istoku regije, do izražaja dolaze burgun- 
dske sorte iz porodice pinota, od kojih ponajviše pinot crni, a na krajnjim istočnim granicama uz rijeku Dunav ponajbolje se snalaze frankovka te bordoške sorte cabernet sauvignon i merlot (HGK, 2011).

Podregija Hrvatsko Podunavlje prema Pravilniku o zemljopisnim područjima uzgoja vinove loze (NN, 76/19) dijeli se na:

- Vinogorje Srijem (llok, Vukovar, Lovas, Tovarnik, Tompojevci, Bogdanovci, Nuštar, Nijemci, Stari Jankovci, Vinkovci, Ivankovo, Vođinci, Stari Mikanovci, Jarmina, Bošnjaci, Gradište, Trpinja, Tordinci, Markušica, Borovo, Drenovci, Otok, Privlaka, Andrijaševci, Županja, Gunja, Vrbanja, Negoslavci, Cerna, Štitar, Babina Greda),

- Vinogorje Erdut (Erdut, Osijek, Ernestinovo, Semeljci, Šodolovci, Vuka, Bizovac, Čepin, Koška, Bizovac, Valpovo, Petrijevci, Magadenovac, Donji Miholjac, Podravska Moslavina, Viljevo, Marijanci, Belišće, Vladislavci, Antunovac),

- Vinogorje Baranja (Beli Manastir, Kneževi Vinogradi, Popovac, Draž, Čeminac, Jagodnjak, Bilje, Petlovac, Darda).

\section{Vinogorje Baranja}

Postoji dugogodišnja tradicija uzgoja grožđa i proizvodnje vina na području vinogorja Baranja. To je izrazito ravničarski kraj, kojeg na sjeveru nadvisuje brdo "Banska kosa" (241 m), i idealan je za uzgoj vinove loze. S tim dobrim uvjetima vjerojatno je povezano i ime "Baranja", koja prevedena s mađarskog izvornika znači „vinska majka“. Posebnost vinogorja su gatori (vinski podrumi) u surducima (strmi, usječeni putevi u planini). Idealne uvjete za uzgoj vinove loze i proizvodnju vina prepoznali su i Rimljani koji su još prije 2000 godina Bansku kosu prozvali "Mons aureus" ili Zlatno brdo, što su tisuću godina poslije potvrdili Nijemci koji su ga nazvali Goldberg. Banska kosa, jedno je od najkvalitetnijih vinogradarskih položaja. Pruža se u pravcu jugozapad-sjeveroistok između Belog Manastira i Batine, dužine oko 21 kilometra i širine 5 kilometara (Predojević, 2016). Iznimno plodno tlo, uz pogodnu mikroklimu, uvjetovanu blizinom Dunava, osigurava glavne preduvjete za uzgoj kvalitetnog grožđa, te proizvodnju vina sa zaštićenom oznakom izvornosti ili zaštićenom oznakom zemljopisnog podrijetla. Kombinacija žutih poroznih sedimenata uzrokovanih vjetrovima koji pušu s Dunava i bogatog crnog tla daje tlo prikladno za uzgoj vinove loze. Žuti talog daje mineralnost, a crna tla obiluju hranom potrebnom za rast i razvoj loze. Blaga padina Banske kose okrenuta ka jugu štiti vinograde od jakih sjevernih vjetrova i osigurava dobru osunčanost svakog grozda (Belje_web).

\section{Klimatske prilike}

Razvoj vinove loze usko je povezan s temperaturom zraka. Sume temperatura u vegetacijskom razdoblju važan su pokazatelj za izbor sorte u pojedinoj vinogradarskoj regiji. Smatra se da je za početak vegetacije potrebna minimalna srednja dnevna temperatura od $10^{\circ} \mathrm{C}$, pa se ta temperatura uzima kao biološka nula i prema njoj se računaju sume temperatura u vrijeme vegetacije (1. travnja-30. listopada), a za cvatnju i oplodnju 20-30 @C (Jackson, 2008). Temperature iznad 40 ㅇ mogu izazvati oštećenja na vinovoj lozi. Isto tako, i ekstremno niske temperature mogu imati negativan učinak na razvoj loze (Mariani i sur., 2009). Vrijeme zrenja grožđa se razlikuje od jedne do druge godine i od jednog vinograda do drugog, ovisno uglavnom o klimi. Svjetlost i toplina povoljno utječu na razvoj grožđa, bolje se akumulira šećer, grožđe dobiva ljepšu boju i manja je mogućnost za razvoj bolesti. Zbog toga je svake godine potrebno pratiti dinamiku dozrijevanja svake sorte (Jackson, 2008). Berba je vrlo važna i mora se pravodobno provesti, jer općenito količina i kvaliteta vina ovisi o tome. Podaci o vremenskim uvjetima, dobiveni su od Državnog hidrometeorološkog zavoda - postaja Beli Manastir (DHMZ, 2013). Prema tim podacima, godišnja temperaturna suma u vegetacijskom razdoblju iznosila je 3780 ㅇ, 
što je više od uobičajenog prosjeka od 3749 ㄷ. Srednja godišnja temperatura zraka je iznosila $11.84{ }^{\circ} \mathrm{C}$ što je više od srednje godišnje temperature od $11.5^{\circ} \mathrm{C}$ za podregiju Hrvatsko Podunavlje (Maletić i sur., 2015).

Godišnje oborine za podregiju Hrvatsko Podunavlje iznose $686 \mathrm{~mm}$, a u vegetacijskom razdoblju 371 mm (Maletić i sur., 2015). Količina oborina u 2013. godini (sa sumom od 797.4 mm), bila je veća od godišnjih oborina za podregiju Hrvatsko Podunavlje, no takav rezultat treba pripisati padalinama u ožujku koji se ne smatra mjesecom u vegetaciji (DHMZ, 2013). Kada se računaju mjeseci u vegetacijskom razdoblju, količina oborina (482.1 mm) je bila veća od godišnjih oborina u vegetacijskom razdoblju za podregiju Hrvatsko Podunavlje.

Grafikon 1 predstavlja odnos temperatura i oborina, iz koje je vidljivo da je mjesec s najvišom prosječnom temperaturom u vegetacijskom razdoblju 2013. godine bio srpanj sa $23^{\circ} \mathrm{C}$, dok je mjesec s najviše oborina bio svibanj (102.4 mm). Imajući u vidu optimalne vrijednosti srednjih dnevnih temperatura potrebnih za dozrijevanje grožđa, srednja dnevna temperatura izmjerena u srpnju optimalna je za fenofazu dozrijevanja grožđa, pogotovo ako se uzme u obzir činjenica da nijedan dan u srpnju nije padao ispod $18{ }^{\circ} \mathrm{C}$, što se smatra minimumom za normalno dozrijevanje grožđa (Jackson, 2008.). To potvrđuje rad Kojić i Jakobek (2015), s obzirom da se vegetativno razdoblje 2013. godine pokazalo povoljnim za izuzetnu kvalitetu grožđa tijekom berbe (Kojić i Jakobek, 2015). Nadalje, neke sorte vina (Cabernet sauvignon, Frankovka, Merlot, Pinot crni) proizvedene iz grožđa uzgojenog s područja vinogorja Baranja, već su pokazala svoj potencijal određivanjem fizikalno-kemijskih parametara, kao i senzorskom procjenom (Kojić i Jakobek, 2019).

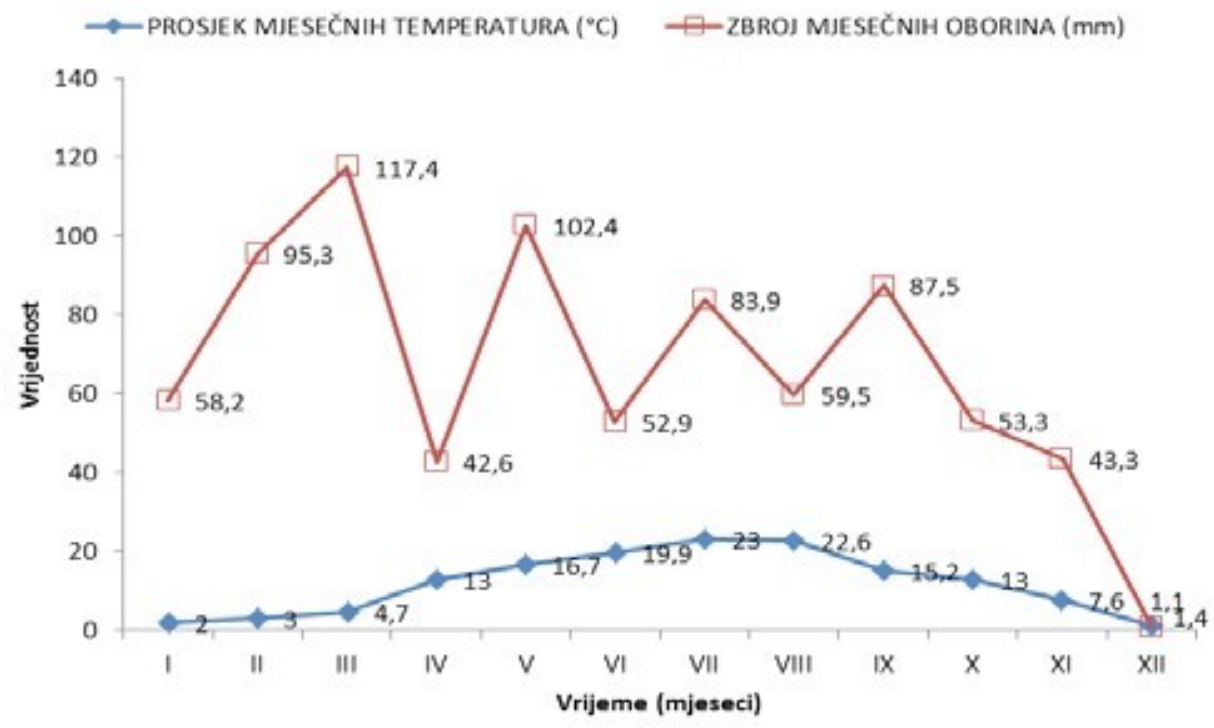

Grafikon 1. Odnos prosječne mjesečne temperature i oborina u podregiji Podunavlje za vinogorje Baranja

Graph 1. The ratio of average monthly temperature and rainfall in the Podunavlje subregion for the Baranja wine-growing hill

Izvor/Source: (DHMZ, 2013) 


\title{
Zaključak
}

Unutar umjerenog klimatskog pojasa, između $42^{\circ} 25^{\prime}$ i $46^{\circ} 30^{\prime}$ sjeverne geografske širine, Republici Hrvatskoj su pruženi izvrsni klimatski uvjeti za uzgoj vinove loze. Vinogradarska podregija Podunavlje se nalazi u uvjetima vinogradarske proizvodne zone C1 sa sumom efektivnih temperatura $1450-1650{ }^{\circ} \mathrm{C}$. Podaci o vremenskim uvjetima za 2013. godinu, dobiveni su od Državnog hidrometeorološkog zavoda (DHMZ) - meteorološka postaja Beli Manastir. Prema tim podacima, godišnja temperaturna suma u vegetacijskom razdoblju iznosila je $3780^{\circ} \mathrm{C}$, što je više od uobičajenog prosjeka od $3749^{\circ} \mathrm{C}$. Srednja godišnja temperatura zraka je iznosila $11.84{ }^{\circ} \mathrm{C}$ što je više od srednje godišnje temperature od $11.5^{\circ} \mathrm{C}$ za podregiju Hrvatsko Podunavlje. Kada se računaju mjeseci u vegetacijskom razdoblju, količina oborina (482.1 mm) bila je veća od godišnjih oborina u vegetacijskom razdoblju za podregiju Hrvatsko Podunavlje (371 $\mathrm{mm}$ ). Vegetativno razdoblje 2013. godine pokazalo se povoljnim za izuzetnu kvalitetu grožđa tijekom berbe (Kojići Jakobek, 2015).

\section{Literatura}

Belje web. https://shop.belje.hr/o-nama/ (21.05.2020.)

Bognār, A. (1972) Stanovništvo Baranje. Hrvatski geografski glasnik, 1 (33-34), 91-138.

Državni hidrometeorološki zavod (DHMZ, 2013.) - meteorološka postaja Beli Manastir. https://meteo.hr/klima. php?section=klima podaci\&param =k2 1\&Godina=2013 (21.05.2020.)

Fazinić, N., Milät, V. (1994) Hrvatskā vina, Mladinska knjiga, Zagreb.

Fazinić, N., Fazinić, M. (1997) Ekologija u službi hrvatskog vinogradarstva. Agronomski Glasnik, 59 (5-6), $401-418$.

Gašparec-Skočić, Lj., Bolić, J. (2006) Hrvatska vina i vinske ceste. Golden marketing-Tehnička knjiga. Zagreb.

Hrvatska gospodarska komora (HGK) - Impressum (2011), Printera grupa d.o.o., Zagreb. http://vinacroatia.hr/wp-content/uploads/2017/01/vina_hrvatske mail1.pdf (21.05.2020.)

Jackson, D. (2001) Monographs in Cool Climate Viticulture - 1. Pruning and Training. Daphne Brasell Associates and Lincoln University Press, Wellington.

Jackson, R. S. (2008) Site selection and climate. U: Wine Science, Principles and Applications, $3^{\text {rd }}$ edition, Academic Press, Elsevier Inc., Burlington, London, San Diego, 239-269.

Kojić, N.., Jakobek, L. (2015) Determination of polyphenolic compounds in red wines from Baranja vineyards. Proceedings of International Conference $15^{\text {th }}$ Ružička days "Today Science - Tomorrow industry". Subarić, D., Jukić, A. (eds.). Osijek and Zagreb: Josip Juraj Strossmayer University of Osijek, Faculty of Food Technology Osijek, Croatian Society of Chemical Engineers, 232-241.

Kojić, N., Jakobek, L. (2019) Chemical and sensory properties of red wines from Baranja vineyards. Proceedings of International Conference $17^{\text {th }}$ Ružička days "Today Science - Tomorrow industry". Tomas, S., Ačkar, Đ. (eds.). Osijek and Zagreb: Josip Juraj Strossmayer University of Osijek, Faculty of Food Technology Osijek, Croatian Society of Chemical Engineers, 63-71.

Maletić, E., Pejić, I., Karoglan-Kontić, J. (2008) Vinova loza - Ampelografi ekologija, oplemenjivanje. Školska knjiga, Zagreb.

Maletić, E., Karoglan Kontić, J., Pejić, I., Preiner, D., Zdunić, G., Bubola, M., Stupić, D., Andabaka, Z., Marković, Z., Simon, S.

Žulj Mihaljević, M. Ilijaš, I. Marković, D. (2015) Zelena knjiga: Hrvatske izvorne sorte vinove loze. Maletić, E., Karoglan Kontić, J, Ilijaš, I. (ur.). Državni zavod za zaštitu prirode, Stega tisak, Zagreb.

Mariani, L., Parisi, S., Failla, O., Cola, G., Zoia, G., Bonardi, L. (2009) Tirano (1624-1930): a long time series of harvest dates for grapevine. Italian Journal of Meteorology, 1, 7-16.

Mirošević, N., Karoglan-Kontić, J. (2008) Vinogradarstvo. Nakladni zavod Globus, Zagreb.

Mirošević, N., Alpeza, I., Bolić, J., Brkan, B., Hruškar, M., Husnjak, S., Jelaska, V., Karoglan Kontić, J., Maletić, E., Mihaljević, B., Ričković, M. Sestan, l., Zoričić, M. (2009) Atlas hrvatskog vinogradarstva i vinarstva. Golden marketing-Tehnička knjiga, Zagreb. Pravilník o zemljópisnim područjima uzgoja vinove loze (NN, 2019/76)

Predojević, Ž. (2016) Zlatno brdo i tisućljetna vinogradarska tradicija. U: Godišnjak Ogranka Matice hrvatske Beli Manastir, 12 (2015), 76-100.

Vina Croatia. http://vinacroatia.hr/hrvatska-vina/regije-vina-croatia/ (21.05.2020.)

Winkler, A. J., Cook, J. A., Kliewer, W. M., Lider, L. A. (1974) General Viticulture. University of California Press, Berkeley, Los Angeles, London.

Zakon o vinu (NN, 2019/32)

van Leeuwen, C., Friant, P., Choné, X., Tregoat, O., Koundouras, S., Dubourdieu, D. (2004) Infl e of climate, soil, and cultivar on terroir. American Journal of Enology and Viticulture, 55, 207-217.'

\section{Tradition and conditions of vine growing in the Baranja subregion}

\begin{abstract}
The main factor that determines the cultivation of vines is the climate. This statement can present by the number of hours of sunshine and the sum of effective temperatures. The Republic of Croatia, with its geographical position, finds its place on the viticultural map of the world. Grapes have been grown for centuries in the area of today's viticultural subregion of Podunavlje, which includes the vineyards of Srijem, Erdut and Baranja. The data used in this paper are related to 2013 for the Baranja wine-growing hill.

Key words: climate, Podunavlje subregion, Baranja vineyards
\end{abstract}

